\title{
Measuring force of infection and vaccine effects on transmission stages in clinical trials of experimental malaria vaccines
}

\author{
Ingrid Felger*, Blaise Genton, Hans-Peter Beck, Tom Smith \\ From Challenges in malaria research \\ Basel, Switzerland. 10-12 October 2012
}

\section{Background}

Molecular parameters of key interest for monitoring the efficacy of anti-malaria interventions are those that quantify effects on transmission or incidence of infection and disease.

Vaccine trials provide regular follow-up samples of both comparator groups. In addition, the clinical episodes are detected and sampled. Provided the spacing of follow up surveys is in the range of 2-8 weeks, the force of infections (FOI) can be determined by genotyping all consecutive samples of all study participants. The molecular FOI is defined by new parasite clones appearing per time interval. Individual clones are identified using highly polymorphic molecular markers in conjunction with high resolution typing. mol FOI is easily detected despite a background of ongoing infections.

Simultaneously, blood samples from trial participants become available for RNA based detection and quantification of gametocytes by qRT-PCR. Vaccine effects on gametocyte prevalence can be detected by targeting gametocyte-specific transcripts.

\section{Materials and methods}

We have evaluated RNA sampling techniques for malaria field surveys. Collecting samples directly into RNAprotect solution gave best results. Gametocytes were detected by qRT-PCR using marker pfs 25.

In our cohort studies asexual parasites were genotyped using marker msp2 and fragment sizing by capillary electrophoresis $[1,2]$. In the vaccine trial (Phase $2 \mathrm{~b}$ vaccine trial of Combination B conducted in Papua New Guinea [3]) a PCR-RFLP methodology was used. We have developed the statistical approaches to determining the actual

Swiss Tropical and Public Health Institute, 4002 Basel, Switzerland number of $P$. falciparum clones aquired per time per individual host, corrected for imperfect detectability [4].

\section{Results}

Molecular parameters describing the P. falciparum infection dynamics were estimated based on high precision genotyping data from cohort studies or from a clinical trial with repeated follow up bleeds at intervals between 2 weeks and 2 months. The full time-series of presence and absence of clones in consecutive samples from one individual forms the basis from which molFOI, duration of infection, and clone detectability were estimated.

${ }_{\text {mol }}$ FOI in vaccinated children from the Combination B vaccine trial was significantly reduced in vaccine recipients only for parasites carrying a 3D7-type $m s p 2$ allele corresponding to 3D7 MSP2 component of Combination B.

\section{Conclusions}

We demonstrated proof of concept of this approach in a vaccine trial of the Combination $B$ malaria vaccine. We propose to consider the mol $\mathrm{FOI}$ as an outcome measurement in vaccine trials and to collect and preserve in the field trial setting in parallel blood samples useful for RNA extractions for monitoring vaccine effects on transmission stages.

Published: 15 October 2012

\footnotetext{
References

1. Schoepflin S, Valsangiacomo F, Lin E, Kiniboro B, Mueller I, Felger I: Comparison of Plasmodium falciparum allelic frequency distribution in different endemic settings by high-resolution genotyping. Malar J 2009, 8:250.

2. Genton B, Betuela I, Felger I, Al-Yaman F, Anders RF, Saul A, Rare L, Baisor M, Lorry K, Brown GV, Pye D, Irving DO, Smith TA, Beck HP, Alpers MP: A recombinant blood-stage malaria vaccine reduces Plasmodium falciparum density and exerts selective pressure on parasite
} 
populations in a phase $1-2 b$ trial in Papua New Guinea. J Infect Dis 2002, 185(6):820-827.

3. Falk N, Maire N, Sama W, Owusu-Agyei S, Smith T, Beck HP, Felger I: Comparison of PCR-RFLP and Genescan-based genotyping for analyzing infection dynamics of Plasmodium falciparum. Am J Trop Med Hyg 2006, 74(6):944-950.

4. Sama W, Owusu-Agyei S, Felger I, Vounatsou P, Smith T: An immigrationdeath model to estimate the duration of malaria infection when detectability of the parasite is imperfect. Stat Med 2005, 24(21):3269-3288.

doi:10.1186/1475-2875-11-S1-050

Cite this article as: Felger et al:: Measuring force of infection and vaccine effects on transmission stages in clinical trials of experimental malaria vaccines. Malaria Journal 2012 11(Suppl 1):O50.

\section{Submit your next manuscript to BioMed Central} and take full advantage of:

- Convenient online submission

- Thorough peer review

- No space constraints or color figure charges

- Immediate publication on acceptance

- Inclusion in PubMed, CAS, Scopus and Google Scholar

- Research which is freely available for redistribution

Submit your manuscript at www.biomedcentral.com/submit 